\title{
THE EXAMINATION OF FOOD WASTE BEHAVIOUR IN HUNGARIAN HOUSEHOLDS
}

\author{
Csaba Borbély*, Rebeka Göbel \\ Hungarian Agriculture and Live Scientists University, Hungary
}

Our current existence on the Earth raises a number of contradictions such as our relation to food. According to the FAO, a third of the food produced does not reach consumers; according to calculations by the World Resources Institute, even if we reduced losses by a quarter, 795 million people would have enough food to feed. This controversial situation gives topicality to the topic, which will only grow as the Earth's population grows by about 80 million people a year and our resources for nourishment are finite. In our research we focused on households within the topic area of food waste generated in the supply chain. This focus of research is considered a difficult one because results could be found only with data logging and this method has several limitations which could distort the results. In our research, 20 households in Kaposvár were asked to log the amount of their food waste for 14 days. We set up five hypotheses before our research.

Keywords: food waste and loss, Hungary, household

\section{Introduction}

The issue of food waste is one of the serious problems of modern social existence. We would probably not find in the history a moment in which there would be no loss of food, but what we are experiencing today is, to put it mildly, unprecedented in the history of mankind. It is also clear that the problem manifests itself differently in different societies around the world, but we find no lossless food use anywhere. Economic development, personal tastes, bad instincts and habits that go with it, the technology available at different stages of the supply chain, along with many other factors, give a nuanced picture of food waste in different parts of the world. We live in a Janus-faced world: while hunger and the consequent secondary diseases are destroying populations in some parts of the world, meanwhile in richer societies overweight - in many cases pathological overweight - and its consequences are high on the list of health problems. The population of our Earth is growing unstoppably and the burning question is how we can provide food for growing populations. We still have reserves in our productive resources, but their limitations are not an issue. Food wastage has been identified as a solution in many places as a treatment option for a given problem. We can see a staggering amount of losses; the problem has risen to a level that we may no longer be able to deal with on a human scale. In many places, we can see government or civil initiatives that are predominantly local to address the problem. With our work, we want to support this activity with objective data and, last but not least, to confirm that the problem is extremely big in this area as well.

\section{Material and methods}

In the methodological part, we would like to clarify why we repeated - with a lower number of items - a research that had already been carried out in Hungary (NÉBIH "Without a Remnant" project), even though there were already international surveys (eg FUSIONS), where expert estimates have been made of domestic food waste in households. The main argument was that although there was already such domestic survey, there was only one of them, so there was a chance that different directions in terms of results would emerge. Knowing the results of the NÉBIH "Without a Residue" project, it can also be stated that we analyzed different background variables in the two researches, different partial results were obtained from the two researches. Comparisons with other research results can be problematic because they do not always work with the same methodology, and in many cases the definition background does not match. Nevertheless, we have found that in the international literature - perhaps precisely because of the low number of studies giving primary results - they almost always refer to the results of research conducted with a different methodology, and we did this in the case of the first hypothesis. In our work we used primary and secondary data sources.

\section{Primary research}

In our research, we used the logging method in 20 households in Kaposvár. It can be stated that the larger number of items would have exceeded the available resources (the NÉBIH project with much better opportunities also "interviewed" only 100 households). The decision on the number of items was thus determined by the possibilities, but at the same time it was clear from the evaluation that the results of a set containing outstanding data were strongly influenced by these values. The possibility of data cleansing also arose, but knowing the international data, we estimated that none of the data sets contained extremely high values (e.g., the highest value in the research is approximately the same as the national average in the UK). Another argument in favour of keeping the entire database was that none of the participants indicated that they did not understand something, something would have slipped into the survey, even though this option was available to them. Thus, overall, we decided to use data from all 20 families in the evaluation, however, we found that the literature that breaks the stick with a low number of items takes a statistically high risk. Participants applied for the survey partly on a voluntary basis and partly through a personal request. We tried to provide all participants with appropriate information, which meant a personal conversation as well as additional information in printed form. Participants in the project were provided with a digital kitchen scale that they could keep after the survey. In the case of the participants in the research, we could not strive for representativeness, so the obtained results can only be considered accurate for the given group, in all other cases it is only informative information.

Respondents had two options to categorise their waste:'non-avoidable food waste' and 'avoidable food waste', which was only partly identical with 
the method used in the NÉBIH (Szakos, SzabóBódi and Kasza, 2019) project. Non-avoidable food waste includes food parts which are generally not considered edible (e.g. egg shell, bones, potato peel). Avoidable food waste products are those that there had been nothing wrong with them originally. We believe this is the more significant of the two categories because the foods listed here are those that we identify as classically discarded food. The results were recorded in Microsoft Excel data tables and evaluated using the given program. We did not enter into a deeper correlation econometric analysis for two reasons: on the one hand, due to the low number of items, and on the other hand, the vast majority of research on the topic only examines the extent of specific annual food waste and loss.

\section{Secondary research}

In terms of secondary sources, we relied primarily on Internet databases. Of these, we used in our work: EUROSTAT (https://ec.europa.eu); the website of the Central Statistical Office (www.ksh. hu). In addition, we reviewed a number of related Internet portals and journals.

\section{Results and discussion}

After reviewing the literature and the research carried out on this topic at the Kaposvár Campus of Szent István University, we set up five hypotheses before our research:

$\mathrm{H} 1$ : The amount of food waste generated in the EU average. which were not consumed in spite of the fact Hungarian households does not exceed

H2: Households cooking several times a week produce less food waste.

H3: Households including a family member with a special diet of some sort produce less food waste.

H4: The more children a family has, the larger amount of food waste is produced.

H5: Households of retired persons generate less food waste.

\section{The amount of food waste}

During the analysis of the database, we firstly examined the general results of the logging data of the survey participants, which - due to the same methodology - were well comparable with the results of the NÉBIH "Without Remnants" programme (Table 1).

In our first hypothesis we stated that the food waste of households in Hungary is lower than the EU average. This assumption was based on the 2010 European Commission report (European Commission, 2010), which analyzed food wastage in the then 27-member EU, based in part on national statistics and in part on expert estimates, supported, inter alia, by data tables. In this survey, the EU average of food waste generated by households was $76 \mathrm{~kg} /$ person/year, while the domestic estimate was $39 \mathrm{~kg} /$ person/ year. Comparing our research results, we used the results of the EU project, "Fusions" (Stenmarck et al., 2016), in which the amount of food waste at different stages of supply was estimated for the EU-28 (Table 2). We chose this project because we wanted to work with the most up-to-date data possible for the whole of the Union.

Table 1 Composition of food waste in own research and in NÉBIH project

\begin{tabular}{|l|c|c|}
\hline Name & Own research $(\mathrm{kg})$ & NÉBH project $(\mathrm{kg})$ \\
\hline Avoidable food & 26.1 & 33.1 \\
\hline Non-avoidable food & 36.4 & 32.1 \\
\hline Potentially avoidable food & n.d. & 2.8 \\
\hline
\end{tabular}

Source: Own research (2018) and Szabó-Bódi and Kasza (2017)

Table 2 Amount of food waste in the supply chain (EU-28)

\begin{tabular}{|l|c|c|}
\hline Sector & Food waste and loss (million tons) & Food waste and loss (kg per capita) \\
\hline Production & 9.1 & 18 \\
\hline Processing & 16.9 & 33 \\
\hline Commerce & 4.6 & 9 \\
\hline Restaurants & 10.5 & 21 \\
\hline Households & 46.5 & 92 \\
\hline Total & 87.3 & 173 \\
\hline
\end{tabular}

Source: Stenmarck et al., 2016
Comparing our result $(62.5 \mathrm{~kg} /$ per capita/ year) to the result of a survey made across several countries ( $92 \mathrm{~kg} /$ per capita/year) we can conclude that our first hypothesis is confirmed, i.e. the amount of food waste in Hungarian households is lower than the EU average.

\section{The effect of cooking on the amount of food waste}

Our second hypothesis was that households that cook more than once a week generate less food waste. The relevant background variable of our questionnaire (Do you bake or cook at home?) provided respondents with five options: (yes, every day; yes, several times a week; yes, once or twice a week; yes, but less often than weekly; hardly or never). When evaluating the results, we found that all participants cook at least once a week, so no one was classified in the last two categories. Knowing the effect of cooking and baking on food waste, we made another statement within Hypothesis 2 before we started analyzing the results. The possibility of cooking and baking can be recycled from previous food scraps, in addition, in the case of food made according to one's own taste, presumably less leftovers are generated. Another advantage is that those who cook for themselves or their families can calculate the planned amount well, which also points in the direction of decreasing food waste. For this reason, we consider it logical that we can count on less "avoidable" food waste, but at the same time there will be more "by-products" and "unavoidable" waste during cooking and baking (egg, potatoes, vegetable peels). The results are shown in Table 3.

The data in Table 3 basically did not confirm our assumptions. We believe that the low number of items already makes its mark on the results, but since all 20 data recordings were professionally good, we did not question what was described in them. However, there was a family where we saw very high values compared to the others. Six people live in this family ( 2 active adults, 2 retirees, 2 school children) with an annual total food waste production of $136.64 \mathrm{~kg}$ per capita, of which the avoidable loss was more than $100.77 \mathrm{~kg}$ per capita.

On the whole, our results do not completely confirm this hypothesis. Based on our data this hypothesis should be discarded but after filtering out the extreme values and with a larger item number it would be probably possible to confirm the second hypothesis. 
Table 3 The effect of baking and cooking on the amount of food waste

\begin{tabular}{|c|c|c|c|c|}
\hline \multirow[t]{2}{*}{ Baking, cooking } & \multicolumn{2}{|c|}{ Avoidable waste (kg/capita/year) } & \multicolumn{2}{|c|}{ Non-avoidable waste (kg/capita/year) } \\
\hline & value & dispersion & value & dispersion \\
\hline Every day $(n=4)$ & 35.23 & 43.75 & 46.17 & 12.22 \\
\hline Several times a week $(n=12)$ & 24.52 & 18.37 & 29.94 & 22.09 \\
\hline Once or twice a week $(n=4)$ & 21.58 & 19.07 & 46.14 & 40.50 \\
\hline
\end{tabular}

Source: Own research (2018)

mean without extreme value in the given group $(n=3)$

Table 4 Food waste habits of special diets in our research

\begin{tabular}{|l|c|c|c|}
\multirow{2}{*}{ Name } & \multicolumn{2}{|c|}{ Avoidable waste (kg per capita/year) } & \multicolumn{2}{|c}{ Non-avoidable waste (kg per capita/year) } \\
\cline { 2 - 4 } & value & dispersion & value \\
\hline Special diets & 17.33 & 19.36 & 31.90 \\
\hline Normal diets & 30.78 & 25.69 & 38.86 \\
\hline
\end{tabular}

Source: $\quad$ Own research (2018)

Table 5 The effect of the number of children on the amount of food waste

\begin{tabular}{|l|c|c|c|c|}
\multirow{2}{*}{ Name } & \multicolumn{2}{|c|}{ Avoidable waste (kg per capita/year) } & \multicolumn{2}{c|}{ Non-avoidable waste (kg per capita/year) } \\
\cline { 2 - 5 } & value & dispersion & value \\
\hline No children & 13.09 & 8.97 & 34.79 \\
\hline $\mathbf{1}$ child & 27.11 & 20.77 & 43.93 \\
\hline $\mathbf{2}$ children & 58.85 & 37.49 & 22.10 \\
\hline $\mathbf{3}$ children & 25.20 & 21.23 & 21.56 & 33.51 \\
\hline
\end{tabular}

Source: Own research (2018)

\section{Food waste habits of special diets}

In our Hypothesis 3, we used the assumption that if there is at least one person in the household who requires a special diet, the amount of food waste there will be less than the average of those on a normal diet. In our research, special diets were mainly people with gastroenterological diseases (lactose, flour sensitivity, long-term diet after surgery), diabetics, or dieters. Our hypothesis was based on the assumption that they could not eat everything, and in many cases they could eat from narrow food selection and these foods are very expensive in most of cases. In our survey, 7 out of the 20 respondents indicated that someone was living on a special diet in their household. Based on previous research results, we hypothesized that in this group, beyond the basic idea of Hypothesis 3, the amount of avoidable waste is smaller, while the amount of unavoidable waste is higher than the average of all fillers. In our opinion, the more expensive ingredients and the narrow range of dishes made from them encourage the members of this group to pay more attention and save money.

From the data in Table 4, it can be concluded that the amount of food waste for those following a special diet was $49.23 \mathrm{~kg} /$ person/year, which is almost $20 \mathrm{~kg}$ less than for those on a normal diet. Within the results, the amount of avoidable waste in the case of special diets is significantly lower than in the case of normal diets, which is also considered logical. Foods made from expensive, sometimes hard-to-obtain raw materials are valued more by those concerned than those that can be bought at normal prices in almost every commercial unit.

On the whole, this is confirmed by our findings: in households where there is at least one person following a special diet, the total amount of food waste is lower. In addition, we concluded that the lower amounts in the "avoidable" category could possibly be attributed to the specific and more expensive food products.

\section{The effect of the number of children on the amount of food waste}

In the survey, 12 of the 20 households had children under 18 years of age. In our Hypothesis 4, we assumed that the presence of a child in the household increases the amount of food waste, and as the number of children increases, the amount of waste per capita also increases. According to the literature, the taste world, which in many cases varies from child to child, is one of the main reasons for the generation of household food waste. Our research experience has shown that the amount that cannot be avoided depends on a number of factors, so in this chapter we have focused primarily on the avoidable amount that is actually wasted.

In the methodological chapter, we stated that the research was not representative; however, it is necessary to state that the results obtained are therefore informative. The values in Table 5 only partially supported our hypothesis. The amount of avoidable food waste shows an actual increase across three categories; however, this trend seems to be reversed for families with three children. In this group, the results of only two families are included and the value of one is considered as a relatively low one in the examined category ( $10.19 \mathrm{~kg} /$ person/year).

This hypothesis is only partly confirmed by our findings but we assume that with a larger item number the extreme values would not distort the results of the groups to such an extent and the hypothesis could be confirmed. 
Table 6 Retirees v. active people food waste habits

\begin{tabular}{|l|c|c|c|c|}
\multirow{2}{*}{ Name } & \multicolumn{2}{|c|}{ Avoidable waste (kg/capita/year) } & \multicolumn{2}{c|}{ Non-avoidable waste (kg/capita/year) } \\
\cline { 2 - 5 } & value & dispersion & value & dispersion \\
\hline Retirees $(\boldsymbol{n}=2)$ & 13.59 & 2.78 & 49.66 & 7.61 \\
\hline Active poeople $(\mathbf{n}=18)$ & 28.97 & 25.01 & 40.48 & 26.07
\end{tabular}

Source: Own research (2018)
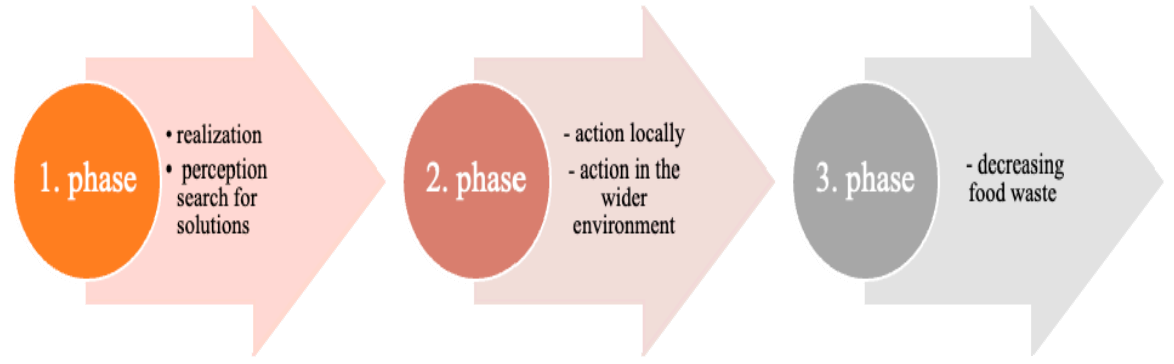

Figure 1 The process of taking action against food waste Source: Own presentation

\section{Food waste habits of retirees}

Some literature highlights that retirees treat food less wastefully than other groups in society. In our study, we meant a retired household where there are no family members of other ages. Two families met this criterion. In addition to the basic hypothesis, we again made additional assumptions, namely that retirees can devote more attention and time to the process of food procurement, cooking, and storage. More thoughtful shopping, more cooking per week, well-planned quantities and careful storage and residual use characterize this group. In Table 6 , the households participating in the study were divided into two groups accordingly. The research results support the hypothesis, although it was somewhat surprising that the amount of total waste was higher, albeit to a small extent, for retirees. The category that is considered more important to us, avoidable food waste, is approximately in the half of the active group, while in the case of unavoidable waste, retirees throw away almost 50\% more. The latter higher value can be attributed to the fact that this group is likely to cook more than once (in one household every day, in the other several times a week), which necessarily leads to more unavoidable losses.

On the whole, our fifth hypothesis is confirmed by our findings: households including only pensioners produce less non-avoidable and more avoidable food waste, which results from the fact that pensioners cook more often than the members of the control group.

\section{Conclusions}

In many places and many times, the practices of controlling food waste generated in households have been described, and we can find many good practices, the application of which could lead to meaningful results. We have found that these practices are familiar to most people (e.g., shopping with a pre-compiled list, reviewing the refrigerator regularly, recycling options, etc.) but are not used consistently and regularly. Why do not we pay more attention to a problem that occurs every day? Why do we only think about trouble when we have a guilty conscience after throwing out more food? For a better understanding of the problem, figure 1 shows the process of action against food waste.

In our view, the biggest problem right now is in the first stage: although people still perceive the problem, which can trigger action on an ad hoc basis, they are not really aware of the seriousness of the issue, so the perception phase is missed by many. In order to achieve a meaningful and lasting result, we need to move on at this point, we need to explain to people how serious the situation is in the area of food waste. There are many aspects to food waste. We see two points of intervention that can be used to reach most people in the $21^{\text {st }}$ century today (without, of course, giving up all other options to improve the situation).

The first area is environmental protection and the sustainability that can be closely linked to it, but perhaps a more sensitive reaction can be elicited by presenting the economic side of the situation. After elaborating on the content of these two main strands, people should be addressed with the results obtained. This information should be the responsibility of all concerned: government agencies, NGOs, educational institutions, everyone who comes into contact with food waste and considers it their responsibility to minimize it.

Campaigns and information events need to be launched in an organized and coordinated way to capture information in people and trigger daily routines with which they can effectively and permanently reduce the amount of food waste.

\section{Acknowledgement}

This research was supported by the "EFOP-3.6.116-2016-00007 sz. Intelligens Szakosodási Program a Kaposvári Egyetemen címú pályázat" project.

\section{References}

SZABÓ-BÓDI, B. - KASZA, Gy. 2017. NÉBIH - Maradék nélkül program. Kutatási eredmények összefoglalása. http://portal.nebih.gov.hu/-/maradek-nelkulprogram-kutatasi-eredmenyek-osszefoglalasa. Letöltés dátuma: 2018 9. 27.

STENMARCK, A. - JENSEN, C. - QUESTED, T. - MOATES, G. 2016. Estimates of European food waste levels. Fusion projekt. ISBN 978-91-88319-01-2. http:// www.eu-fusions.org/phocadownload/Publications/ Estimates\%20of\%20European $\% 20$ food\%20 waste\%20levels.pdf. Letöltés dátuma: 20185. 29.

EUROPEAN COMISSION. 2010. Preparatory study on food waste across EU 27. Technical Report - 2010 - 054. http://ec.europa. eu/environment/eussd/pdf/bio foodwaste report.pdf. Letöltés dátuma: 2018.02.22.

\section{Contact address}

Csaba Borbély, Hungarian Agriculture and Live Scientists University, Kaposvár Campus, e-mail: borbely.csaba@szie.hu

口ロ 